\title{
Extreme long-distance seed dispersal via sheep
}

\author{
Pablo Manzano and Juan E Malo
}

Extremely long seed dispersal distances occur as a result of processes such as ocean drift and tornadoes. However, we have found that large numbers of seeds with different morphologies (Trifolium angustifolium, Daucus carota, Hordeum murinum, and Plantago lagopus) are frequently dispersed equivalent distances while attached to migrating ungulates. We determined experimentally that seeds attached to the fleece of traditional nomadic ("transhumant") sheep are transported distances of up to several hundred kilometers in substantial numbers (ranging from $5-47 \%$ of the initial seed population). Given the current and historical importance of migrating herds of sheep (wild and domestic) on different continents, the results of this study highlight the role of adhesion in long-distance dispersal and support the inclusion of migrating ungulates among forces responsible rapid plant migrations (eg following glaciations, invasion events, or in a future global change scenario). Our results also highlight an unexplored ecological consequence of abandoning nomadism.

Front Ecol Environ 2006; 4(5): 244-248

B iogeographers have long considered the presence of organisms outside their normal distribution range to be important, since this will indicate where the tails of dispersal curves might lie and what the species migration potential might be. Long-distance dispersal (LDD; ie the dispersal of seeds or propagules over distances several orders of magnitude greater than median distances; Higgins et al. 2003a), is a major topic in plant dispersal biology, linked with biogeography (Cain et al. 1998) and conservation ecology issues (Soons and Ozinga 2005). However, studies have been severely constrained by the low proportion of seeds that travel long distances and therefore by the difficulty of gathering data (Higgins et al. 2003a). There is a discrepancy of several orders of magnitude between observed migration rates of plants in the fossil record (100-1000 $\left.\mathrm{m} \mathrm{yr}^{-1}\right)$ and the dispersal capacity actually measured by experimental studies (up to $10 \mathrm{~m} \mathrm{yr}^{-1}$ ). Known as Reid's paradox, it has been a controversial issue in seed dispersal ecology since the end of the 19th century (Clark et al. 1998). Exceptional abiotic dispersal factors such as tornadoes are extremely infrequent and unpredictable, so they do not provide a plausible explanation. Recently, modeling approaches have focused on wind dispersal (Nathan et al. 2002) and dispersal in feces (Pakeman 2001); however, these processes cannot produce sufficiently high dispersal rates to explain the rapid migrations observed in the paleorecord, except in a limited number of plant species and under special circumstances (Higgins et al. 2003b). Only some wind dispersal models and limited experimental data for tropical birddispersed trees provide dispersal distance data per year

TEG, Dpto Ecología, Universidad Autónoma de Madrid, E-28049 Madrid, Spain (pablo.manzano@uam.es) consistent with that found in the paleorecord (Higgins et al. 2003a), and only by a small margin. The paleomigration rates for herbs remain unexplained (Cain et al. 1998) and their predicted migration rates are lower than those for trees (Higgins et al. 2003a).

Seed dispersal by adhesion, or epizoochory (the transport of seeds attached to animal skin), is well-known in biology (Ridley 1930), but little systematic data has been available until recently, mainly because of the methodological difficulty of studying such phenomena (Sorensen 1986). Even fewer studies have examined the efficacy of epizoochory over great distances. However, research on epizoochory by sheep (Fischer et al. 1996) has shown its potential importance in terms of retention time and dispersal distance. Studies have also highlighted the potential of other animals to disperse seeds in this way (Couvreur et al. 2004), even facilitating the spread of non-native species (Sorensen 1986; Constible et al. 2005). Perhaps most striking is the diversity of plant species that can be dispersed by epizoochory (Fischer et al. 1996), among which herbs are especially notable (Sorensen 1986).

Transhumance involves seasonal drives of animals for hundreds of kilometers in search of productive pastures. An ancient method of livestock management in Spain (Ruiz and Ruiz 1986) and other countries (Fischer et al. 1996), it has been progressively abandoned as a result of economic development. The similarities between transhumance and the migratory movements of wild animal herds (Fryxell and Sinclair 1988) provide an opportunity to evaluate the LDD potential of herbivores in general. In this study we used one of the last transhumant sheep flocks in Spain to determine actual seed retention times and dispersal potential. 


\section{Methods}

The route of the merino flock (the breed traditionally used in Spanish transhumance), a herd of about 1500 animals, follows the traditional cattle paths ("cañadas reales") ranging from the Cantabric Mountains, through Spain's northern plateau, Madrid, and the Tajo valley, and finally ending in Extremadura, in SW Spain (Figure 1a). This livestock movement takes place over a period of 1.5 months or more and provides a unique, linear dispersal vector over extremely large distances. The seeds of four herb species common in central Spain, together with their dispersal structures, were collected in the field in September 2003, at the time the sheep flock
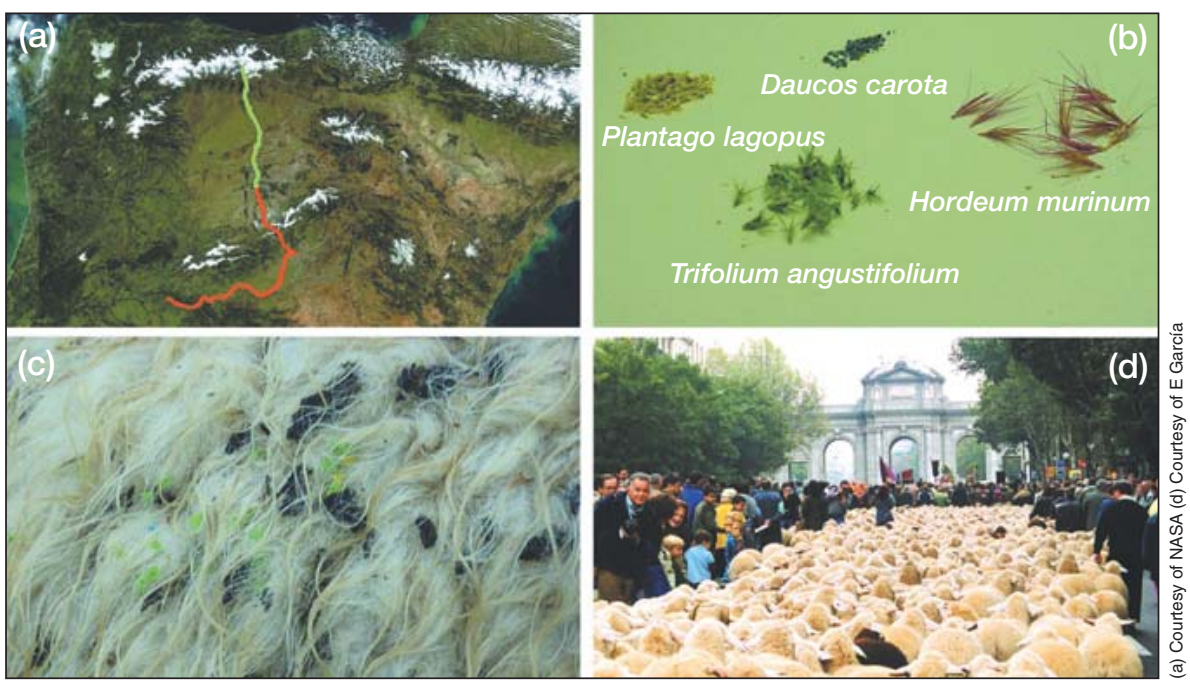

Figure 1. Phases of the experiment. (a) Route followed by merino sheep flock before (green) and after (red) application of seeds to fleece of focal animals. (b) Marked seeds in the lab. (c) Marked seeds on fleece. (d) Flock used in the experiment crossing Madrid city center. began the move towards winter pas-

tures. These herb species were narrowleaf crimson clover (Trifolium angustifolium), carrot (Daucus carota), foxtail barley (Hordeum murinum), and hare's-foot plantain (Plantago lagopus). The propagules were then colormarked with previously tested, water-based lacquer (Fischer et al. 1996; Figure 1b) and placed in three different positions (front, center, and back) on the fleece of each of five castrated rams (wethers) during the annual drive, near the municipality of Coca (Segovia; Figure 1a). In each position, 40 propagules of $T$ angustifolium, 50 of $D$ carota, 12 of $\mathrm{H}$ murinum, and 40 of P lagopus were placed by hand. Wethers are used to help guide the flock by being regularly hand-fed and by wearing cowbells, and were chosen for the experiment because they are easier to handle and similar in behavior to ewes. In fact, they walk within the flock most of the time.

On November 8th, 2003, seeds were spread over one hand which was then gently pressed onto the fleece for a few seconds, simulating the effect of the animal lying on the ground. A sample of wool taken from each animal was used to measure the amount of curling of the wool, by dividing the length of the hair stretched out by length in its curled state. We then followed the flock from Coca (Segovia, $41^{\circ} 13^{\prime} \mathrm{N}$ and $4^{\circ} 32^{\prime} \mathrm{W}$ ) to Torrejón el Rubio (Cáceres, $39^{\circ} 46^{\prime} \mathrm{N}$ and $6^{\circ} 00^{\prime} \mathrm{W}$ ), a 28-day journey with a total distance of about $400 \mathrm{~km}$ (Figure 1a).

Visual counts of the propagules were made while the flock was resting so as not to disturb the animals. The adherence of each plant species was measured as the percentage of propagules remaining on the fleece 2.5 hours after placement. Differences between plant species were assessed using a nested analysis of variance (ANOVA), controlling for the effects of individual (factor "wether") and propagule position (see below). Significance level was set at $P=0.05$.

To determine the persistence of the propagules on the fleece during the rest of the journal, eight further counts were made on November 10th-12th, 14th, 16th, 19th, 26th, and December 3rd. Persistence was measured as the proportion of seeds in the initial count (at 2.5 hours) that remained attached to the the fleece (Figure 1c). A significant number of propagules were still present at the end of the route, so three more counts were carried out on December 17 th, January 7 th, and February 17 th, before the animals were sheared on May 2nd, 2004.

An algebraically tailed dispersal curve (Portnoy and Willson 1993) was fitted to the resulting dataset for every case (four plant species $\mathrm{x}$ five individual sheep $\mathrm{x}$ three positions on each sheep $=60$ in total). The fitted model was:

$$
n=100(t+1)^{a}
$$

where $n$ is the percentage of initially attached propagules present, $t$ is the time, expressed in hours, elapsed since propagule adhesion, and $a$ is the parameter estimated. In order to ensure robust least squares estimates (Quinn and Keough 2002), data were log-transformed to adjust the linearized function:

$$
\ln (n)=\ln (100)+a \ln (t+1) .
$$

The estimate $a$ was used as a descriptor for each of the 60 persistence datasets, and introduced as a dependent variable in an ANOVA test performed with the factors species, wether, and position (nested within factor "wether") as independent variables. A cubic root transformation of $a$ was performed to achieve normality, and significance level was set at $P=0.05$. Only one of the 60 regressions was non-significant $(P=0.1625)$ and was therefore dropped from further analyses. The other 59 regressions were highly significant (mean $P$-value 0.00013; sd $=0.00049$; all cases $P<0.003$ ) and explained 
$65 \%$ of the variance (mean $\mathrm{r}^{2}=0.648$; average data can be found in WebTable 1). Afterwards, the correlation between mean propagule persistence on wethers and wool curling was tested.

To describe the seed deposition with time (seed rain, sr) inferred from the mean values of the above model, we used the negative of the derivative of equation (1), ie:

$$
s r=-(100 a(t+1) a-1)
$$

whose linearized form for representation purposes is:

$$
\ln (s r)=\ln (100)+\ln (-a)+(a-1) \ln (t+1) .
$$

\section{Results and discussion}

The mean adherence potential of propagules after 2.5 hours differed significantly between plant species $\left(\mathrm{F}_{3,42}=\right.$ 8.49; $P<0.001$ ), with $T$ angustifolium showing the greatest attachment potential (mean $51.5 \%$; sd $=4.48$ ). The adherence values for the three other species $(D$ carota $33.73 \%$, sd $=4.66 ;$ H murinum $29.44 \%$, sd $=4.22 ;$ P lagopus $32 \%$, sd $=6.33$ ) were similar, even though their propagules have very distinct morphologies. In fact, $P$ lagopus capsules get attached by means of sparse hairs present on corolla-lobes, a structure that contrasts with the hook- or spine-bearing appendages considered typical for epizoochory (Weiher et al. 1999). Several studies have noted that seeds lacking obvious adaptations for adhesion can nonetheless become attached to animal furs (Fischer et al. 1996; Couvreur et al. 2004).

The selected model proved to be a good descriptor of the persistence curve (WebTable 1) and persistence is easily described by a linear equation after log-transformation of variables. The high goodness-of-fit contrasts with the usual difficulties of finding appropriate statistical

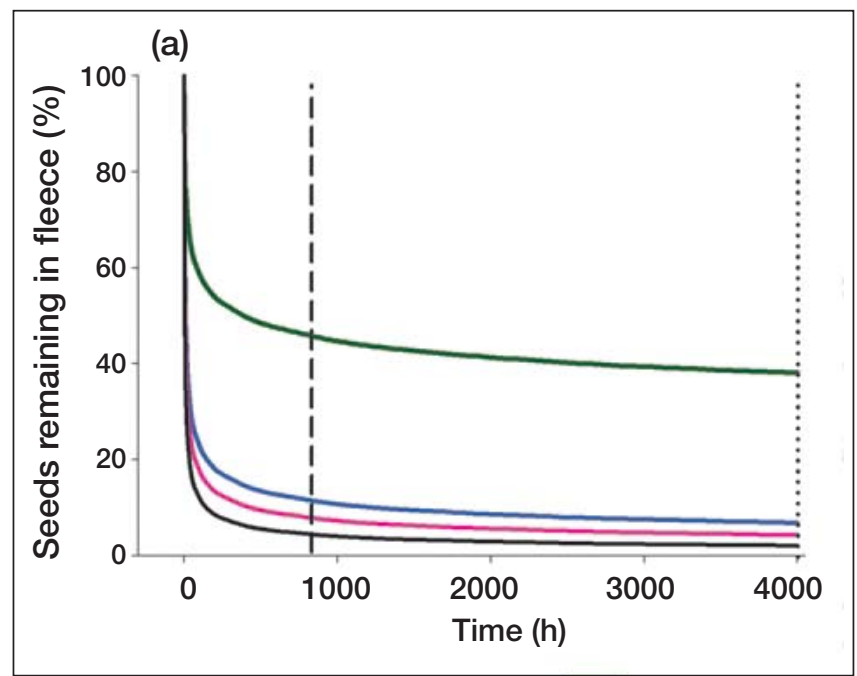

models that adequately describe dispersal data (Cain et al. 2000), and offers a useful approach to quantifying attachment potential of plant propagules.

Seeds attached to sheep fleece show extremely high persistence; following the 28-day, 400-km journey (Figure 2a; WebFigure 1), a total of $46.9 \%$ of T angustifolium, $12.3 \%$ of D carota, $9.6 \%$ of $H$ murinum, and $4.9 \%$ of $P$ lagopus propagules remained attached to the fleece. At the time of shearing (4000 h after seed placement), persistence of seeds in the fleece was still $38.1 \%, 6.93 \%, 5.06 \%$, and $2.15 \%$, respectively. For each of the studied plant species, these data are the greatest dispersal distances ever recorded. They exceed the greatest dispersal distances measured so far in other animals by at least two orders of magnitude (4 km vs $400 \mathrm{~km}$; Higgins et al. 2003a), and provide enough distance to solve Reid's paradox on Holocene migration of herbs (Cain et al. 1998; Clark et al. 1998; Pakeman 2001; Higgins et al. 2003b). The final tail of the distribution is so large (Figure 2a; WebFigure 1) that, by some definitions, it cannot be described as LDD, as this concept is sometimes identified as the final $1 \%$ of the distribution spectrum (Cain et al. 2000).

Epizoochory differs from other mechanisms of animalmediated dispersal, such as endozoochory (dispersal by ingestion and later defecation), in that the resulting seed deposition is not clumped in space and time, but evenly distributed (Sorensen 1986). Seed detachment from the fleece over the entire dispersal period can be mathematically described as a seed rain function (Figure 2b). Its decay is slower for more persistent propagules, so that seed dispersal among species with efficient attachment structures continues for a greater length of time (and over a potentially greater distance). They are therefore able to disperse more efficiently. Dispersal efficiency by means of epizoochory also has the advantage, compared to endozoochory, that attached seeds are not subjected to losses via digestion or secondary seed predation in feces.

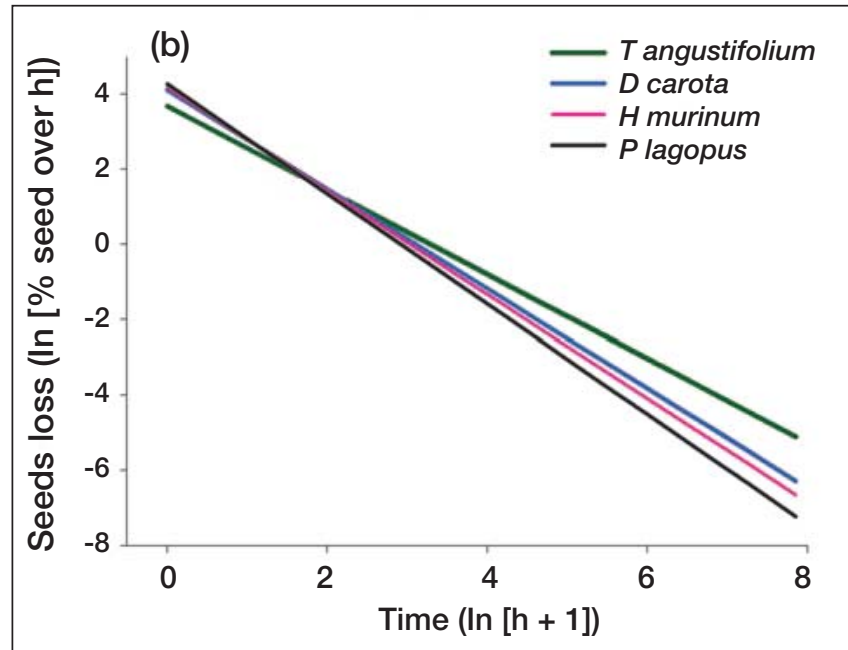

Figure 2. Retention pattern of propagules and seed loss in fleece. (a) Plots display equation (1) for average persistence parameter values. The end of the $400 \mathrm{~km}$-long journey is represented by a vertical dashed line, and the time of shearing by a vertical dotted line. (b) Seed rain, calculated for the mean persistence parameter values in equation (4). 
Even among sheep of the same breed, we found that the "wether" factor had a significant effect on seed retention time (WebTable 2). Mean persistence seems to be related to the curliness of the fleece (Pearson $r=0.733$; $d f=4$; $P=0.158$ ) but no significant difference was found, probably because of the small number of wethers used in the study. A similar relation has been observed among the furs of several mammal species in the laboratory (Couvreur et al. 2004), where the greater range of hair types used in the study results in major retention differences among animals.

Persistence of seeds in fleece varied significantly between plant species (WebTable 2), but $T$ angustifolium was the only species to show a significantly higher persistence on the animals than the others (HSD test: $P<0.001$ in all comparisons). Nevertheless, a significant retention was found even among propagules without specialized attachment morphology. The fact that nearly $5 \%$ of $P$ lagopus propagules reached the winter pastures $400 \mathrm{~km}$ away and one month after propagule attachment ( $2 \%$ persisted for 6 months in the fleece) has important implications.

Propagules that are able to disperse effectively, despite the lack of obvious adhesion adaptations, seem to be quite common (Ridley 1930; Fischer et al. 1996); this means that epizoochory linked to migratory species can be an important LDD vector for seeds/fruits with diverse morphologies. In fact, experimental approaches have shown that propagules of many species can attach to, and remain within, the sheep fleece or the straight fur of wild and domestic species, for the equivalent of several hours under natural conditions (Couvreur et al. 2004; Römermann et al. 2005). Such retention times correspond to dispersal distances of several kilometers if the animals are moving in a single direction. However, morphology did play a role in the attachment and retention of the seeds studied, and the propagules with the most efficient adhesive mechanism ( $T$ angustifolium) showed the greatest dispersal distance (Römermann et al. 2005).

Our study was carried out using plant species that had ripe seeds available in the field at the time of the experiment (autumn). However, in regions with a Mediterranean climate, seed availability and therefore number of seeds potentially transported is higher in spring. We therefore expect transport to be a frequent phenomenon both northwards and southwards. In other arid and semiarid environments where migrating herds are moved in response to changing pasture productivity (and seeding) peaks (Fryxell and Sinclair 1988), we can expect the same pattern of sustained LDD. However, in higher latitudes, where seed production is concentrated at the end of summer (Hülber et al. 2005) northward dispersal events could happen only during itinerant grazing movements (up to $100 \mathrm{~km}$ long; Fischer et al. 1996) within a single season. An alternative option would imply seed permanence in fleece during the winter dormancy typical of species from cold areas (Ortega et al. 1997).

\section{Conclusions and future guidelines}

Assuming that the behavior of propagules on the fur of wild animals is comparable to that in our findings (Couvreur et al. 2004), part of the answer to the paradox of LDD may lie in adhesive dispersal. Epizoochory has long been observed in migrating wild animals (eg Berthoud 1892) and such migrations were both important and widespread in the Pleistocene (Rivals et al. 2004) and still take place in some regions. Large, migrating herbivores play an important role in the dispersal of plants, and this may have been complemented or supplanted by nomadic herds in regions ranging from the Mediterranean (Ruiz and Ruiz 1986) to the Arctic (Ingold 1986). Sheep's wool contains large numbers of viable seeds at the time of shearing and the total number of seeds transported can be high (Manzano and Malo unpublished). Furthermore, epizoochory is not the only way plants are dispersed by nomadic animals; dispersal via the feces of both wild and domesticated animals can also result in long dispersal times (Ridley 1930; Manzano et al. 2005).

LDD may be a critical mechanism for plants to escape the effects of global climate change. Many plants have specific genetic adaptations to local conditions (eg the North American prairie plant Chamaecrista fasciculata; Etterson 2004), highlighting the potential importance of migration mechanisms to plant species faced with rapid climatic changes. However, if LDD depends on large herbivore migrations, this is highly unlikely to continue in today's world. Large wild herbivores have either disappeared or are no longer able to migrate long distances, while the vectors that could substitute for them (ie nomadic herds) are disappearing as a result of economic development. In view of increasing habitat fragmentation, losses caused by human activities, and the consequences for plant migrations (Higgins et al 2003b), the waning of nomadism may have important implications for future plant biodiversity, as it had for soil fertility and plant productivity in Africa in the 1970s and 1980s that culminated in the Sahel famine crisis (Fryxell and Sinclair 1988). In addition, the spread of invasive plant species may be increased by unnatural adhesive dispersal, a more common LDD mechanism for non-native species than endozoochory (Sorensen 1986; Constible et al. 2005), on artificially transported animals.

Research should now focus on the current relevance for plant dispersal of long-range animal movements (either wild or nomadic herds, or agricultural and recreational transport) and on better assessing factors that determine the efficiency of epizoochory. A better understanding of seed transport by animals along corridors and between landscape patches is also needed, in order to guide conservation actions for species and landscapes (Soons and Ozinga 2005). In addition, trade-offs potentially involved in plant traits associated with adhesive dispersal need further assessment. Those trade-offs include a more adhesive morphology causing increased grooming behavior (Sorensen 1986), thus reducing the final dispersal dis- 
tance, or a reduced seed mass that increases the adhesive transport efficiency (Römermann et al. 2005) but also decreases the recruitment success.

\section{Acknowledgements}

We thank L Álvarez and ME Hidalgo for allowing us to work with their animals; J Garzón for making this work possible; S Martos, AM Baena, SD Pastor, Q Wauquiez, JG Vicente, T Sainz, and AI del Cueto for field assistance; and L Manzano for literature assistance. F Suárez, CC Nice, JR Ott, and especially MA Huston thoroughly reviewed earlier versions of this manuscript. This study was supported by the Spanish Ministry of Education and Science (project CICYT REN2003-01562 and FPU fellowship to PM).

\section{References}

Berthoud EL. 1892. A peculiar case of plant dissemination. Bot Gaz 17: 321-26.

Cain ML, Damman H, and Muir A. 1998. Seed dispersal and the Holocene migration of woodland herbs. Ecol Monogr 68: 325-47.

Cain ML, Milligan BG, and Strand AE. 2000. Long-distance seed dispersal in plant populations. Am J Bot 87: 1217-27.

Clark JS, Fastie C, Hurtt G, et al. 1998. Reid's paradox of rapid plant migration - dispersal theory and interpretation of paleoecological records. BioScience 48: 13-24.

Constible JM, Sweitzer RA, Van Vuren DH, and Schuyler DA. 2005. Dispersal of non-native plants by introduced bison in an island ecosystem. Biol Invasions 7: 699-709.

Couvreur M, Vandenberghe B, Verheyen K, and Hermy M. 2004. An experimental assessment of seed adhesivity on animal furs. Seed Sci Res 14: 147-59.

Etterson JR. 2004. Evolutionary potential of Chamaecrista fasciculata in relation to climate change. II. Genetic architecture of three populations reciprocally planted along an environmental gradient in the Great Plains. Evolution 58: 1459-71.

Fischer SF, Poschlod P, and Beinlich B. 1996. Experimental studies on the dispersal of plants and animals on sheep in calcareous grasslands. J Appl Ecol 33: 1206-22.

Fryxell JM and Sinclair ARE. 1988. Causes and consequences of migration by large herbivores. Trends Ecol Evol 3: 237-41.

Higgins SI, Nathan R, and Cain ML. 2003a. Are long-distance dispersal events in plants usually caused by nonstandard means of dispersal? Ecology 84: 1945-56.

Higgins SI, Lavorel S, and Revilla E. 2003b. Estimating plant migration rates under habitat loss and fragmentation. Oikos 101: 354-66.

Hülber K, Ertl S, Gottfried M, et al. 2005. Gourmets or gourmands? Diet selection by large ungulates in high-alpine plant communities and possible impacts on plant propagation. Basic Appl Ecol 6: 1-10.

Ingold T. 1986. Reindeer economies and the origins of pastoralism. Anthropol Today 2: 5-10.

Manzano P, Malo JE, and Peco B. 2005. Sheep gut passage and survival of Mediterranean shrub seeds. Seed Sci Res 15: 21-28.

Nathan R, Katul GG, Horn HS, et al. 2002. Mechanisms of longdistance dispersal of seeds by wind. Nature 418: 409-13.

Ortega M, Levassor C, and Peco B. 1997. Seasonal dynamics of Mediterranean seed banks along environmental gradients. J Biogeogr 24: 177-95.

Pakeman RJ. 2001. Plant migration rates and seed dispersal mechanisms. J Biogeogr 28: 795-800.

Portnoy S and Willson MF. 1993. Seed dispersal curves: behavior of the tail of the distribution. Evol Ecol 7: 25-44.

Quinn GP and Keough MJ. 2002. Experimental design and data analysis for biologists. Cambridge, UK: Cambridge University Press.

Ridley HN. 1930. The dispersal of plants throughout the world. Ashford, UK: L Reeve \& Co.

Rivals F, Kacimi S, and Moutoussamy J. 2004. Artiodactyls, favourite game of prehistoric hunters at the Caune de l'Arago Cave (Tautavel, France). Opportunistic or selective hunting strategies? Eur J Wildl Res 50: 25-32.

Römermann C, Tackenberg O, and Poschlod P. 2005. How to predict attachment potential of seeds to sheep and cattle coat from simple morphological seed traits. Oikos 110: 219-30.

Ruiz M and Ruiz JP. 1986. Ecological history of transhumance in Spain. Biol Conserv 37: 73-86.

Soons MB and Ozinga WA. 2005. How important is long-distance seed dispersal for the regional survival of plant species? Divers Distrib 11: 165-72.

Sorensen A. 1986. Seed dispersal by adhesion. Annu Rev Ecol Syst 17: 443-63.

Weiher E, van der Werf A, Thompson K, et al. 1999. Challenging Theophrastus: a common core list of plant traits for functional ecology. J Veg Sci 10: 609-20. 
WebTable 1. Average variance $\left(r^{2}\right)$ explained by parameter $a$ of the models fitted to propagule persistence on fleece data. Valid $n$ include only regressions with $P$-value $<0.05$ (all cases but one) which are used for further analysis (see Methods)

\begin{tabular}{lcccc}
\hline & \multicolumn{4}{c}{ Variance explained by model parameters } \\
& Mean & sd & Range & Valid $n$ \\
\hline T angustifolium & 0.720 & 0.208 & $0.257-0.956$ & 15 \\
D carota & 0.667 & 0.159 & $0.364-0.919$ & 15 \\
H murinum & 0.483 & 0.209 & $0.216-0.776$ & 14 \\
P lagopus & 0.712 & 0.186 & $0.213-0.923$ & 15 \\
\hline
\end{tabular}

WebTable 2. Effects of plant species, wether, and placement position on propagule persistence measured through the parameter a. Statistically significant values in the ANOVA test at $\boldsymbol{P}=\mathbf{0 . 0 5}$ are shown in bold

\begin{tabular}{lccccc}
\hline Effect & SS & $d f$ & $M S$ & $F$ & \multicolumn{1}{c}{$P$} \\
Wether & $\mathbf{0 . 1 6 2}$ & $\mathbf{4}$ & $\mathbf{0 . 0 4 0}$ & $\mathbf{3 . 1 1 3}$ & $\mathbf{0 . 0 2 5}$ \\
Species & $\mathbf{0 . 6 5 3}$ & $\mathbf{3}$ & $\mathbf{0 . 2 1 8}$ & $\mathbf{1 6 . 7 2 7}$ & $<\mathbf{0 . 0 0 1}$ \\
Position [wether] & 2.552 & 10 & 0.026 & 1.962 & 0.063 \\
Error & 0.546 & 42 & 0.013 & - & -
\end{tabular}

WebFigure 1. Regression data and regression plots. Bubble area represents the frequency of cases observed. Resulting regression plots for the mean a parameter values of equation 2 (see Materials in text) are also displayed
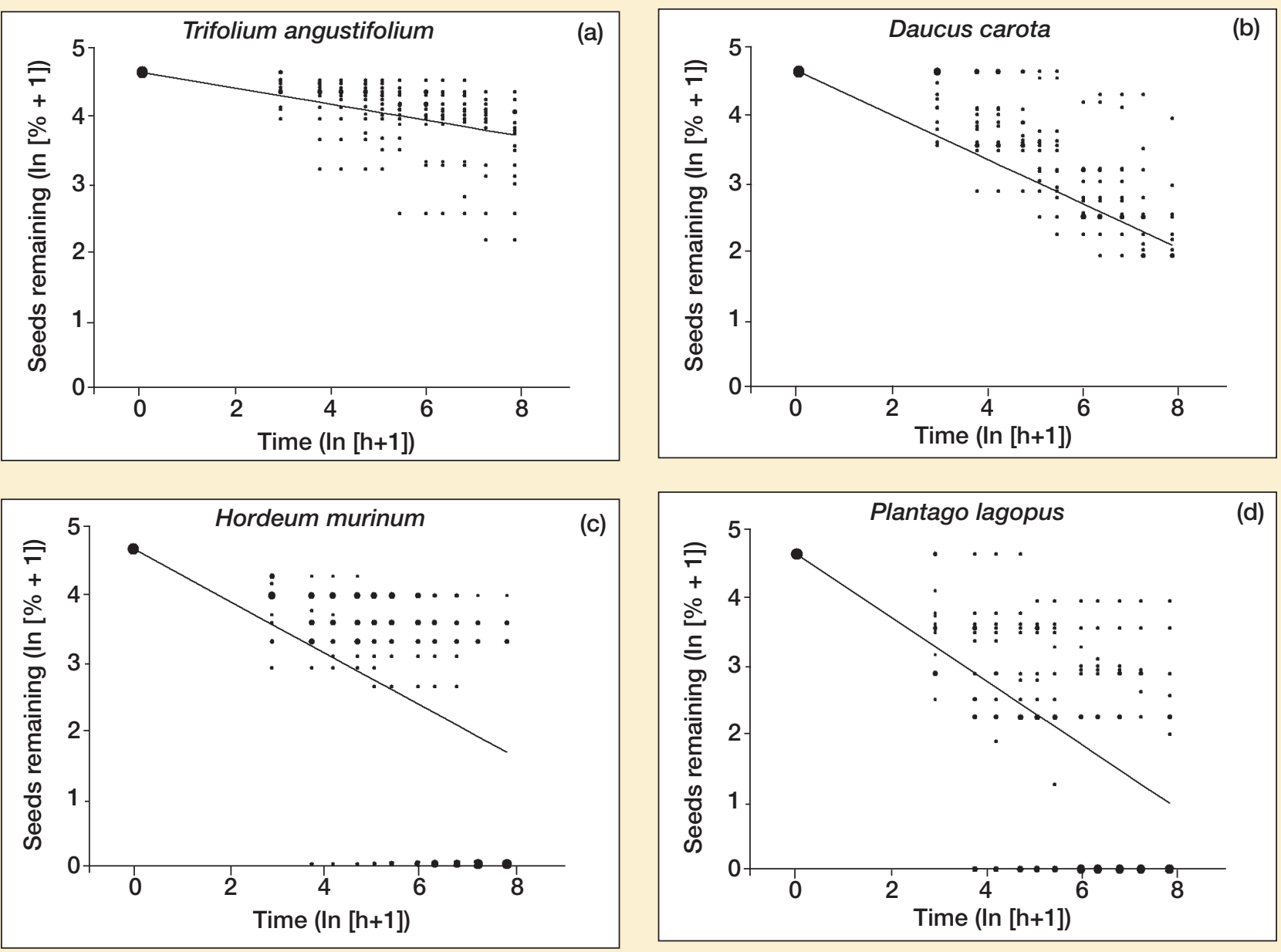